\title{
THE ORIENTATION OF THE HEART AND THE APPEARANCE OF ITS CHAMBERS IN THE ADULT CADAVER
}

\author{
BY \\ ROBERT WALMSLEY \\ From the Department of Anatomy, St. Salvator's College, University of St. Andrews
}

Received January 30, 1958

The gross anatomy of the heart has been studied for hundreds of years and doctors have long been familiar with its main features. Developments in clinical practice in the last 25 years and particularly in the last decade demand, however, a detailed knowledge of certain aspects of cardiac anatomy that is not always available in current text-books. This is apparent if one considers the necessity for the radiologist or clinician screening cardiac patients to be familiar with the detailed anatomy of the various chambers and vessels whose shadows he is inspecting. Again the surgeon engaged on intracardiac surgery must be familiar not only with the gross anatomy of the cardiac chambers but with the minute anatomy, location, and relations of the valve cusps. The clinician at the bedside is helped in his understanding of physical signs by the ability to visualize the chambers of the heart in their proper relationship to one another and their orientation within the thorax.

It seemed apposite therefore, to re-investigate the anatomy of the heart by examining it in situ. A series of sections of entire thoraces were made and studied, some of them having been cut transversely and others in the two oblique planes that allowed the form of the heart and the great vessels to be compared with the right and left anterior oblique views as seen on radioscopy. The primary purpose of this paper is to illustrate and comment on selected sections cut in these planes, but no attempt is made either to review all aspects of the gross anatomy of the heart, or to discuss the distortion that may occur in it as the result of pathological changes.

\section{Right Heart and Left Heart}

The terms "right heart" and "left heart" are commonly used in clinical practice and developmentally these terms are correct and indicate precisely the relationship of the right chambers to those of the left in the young embryo.

In the $10 \mathrm{~mm}$. human embryo, for example, when the septum primum of the atrial septum is well established and the muscular part of the ventricular septum has appeared, the heart is an almost symmetrical structure: the two right chambers lie directly to the right of those of the left heart, and the septa between the atria and between the ventricles lie almost in the mid-line (Fig. 1).

Throughout development and even into adult life, the atrial and ventricular septa remain approximately "in line" with each other and thus allow a plane, which is here referred to as the "plane of the septa", to be defined. The plane of the septa is considered as being indicated by a line which passes from the anterior interventricular groove (or the associated artery if the groove.is not evident) to the posterior attachment of the atrial septum. This line sometimes passes through the substance of the ventricular septum but frequently lies along the right face of this septum.

It is not proposed in this communication to consider the details of the rotation of the heart nor the factors that may be involved in it, but certain facts would appear to be relevant. The first of these is that rotation commences shortly after the $10 \mathrm{~mm}$. stage so that the anterior interventricular sulcus is displaced towards the left and the posterior attachment of the atrial septum towards the right, and in consequence the right heart comes to lie not only to the right of the left heart but to an 


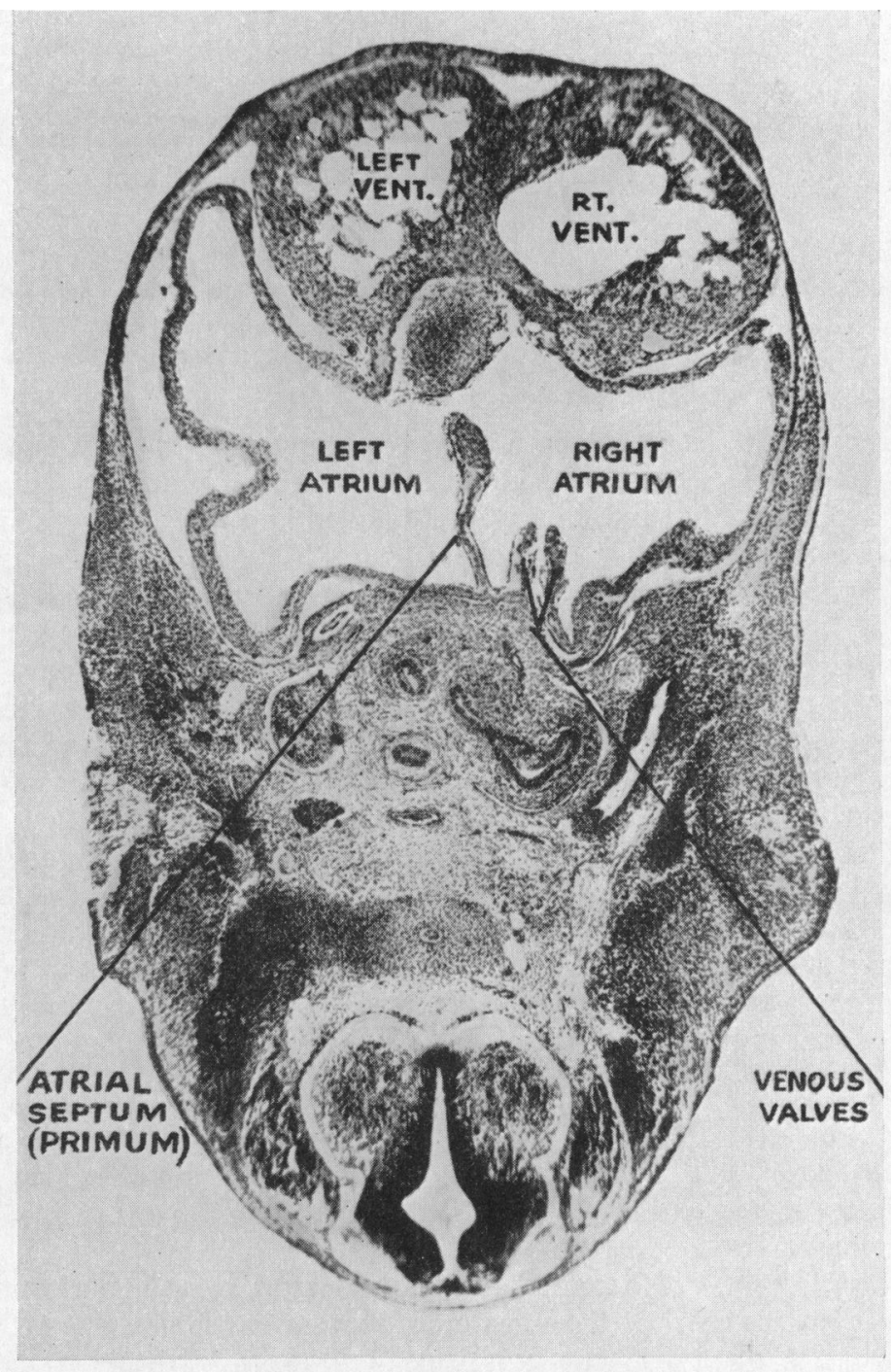

FIG. 1.-Transverse section of thorax of $10 \mathrm{~mm}$. human embryo. The septum primum partially separates the right and left atria (an ostium primum being present) and in this particular section the two ventricles are seen to be completely separated by the muscular part of the ventricular septum. The septa lie almost in the midline and the chambers comprising the right heart therefore lie directly to the right of those of the left heart. Conventionally an embryo is featured with its dorsal surface uppermost and its ventral surface downwards but in order to maintain uniformity among the figures of this article this embryo is shown with its dorsal surface directed towards the foot of the page. The right side of the embryo is therefore on the reader's right and the left side on his left. Magnification, $\times 150$. 
increasing degree, in front of it. In the $4 \frac{1}{2}$ months foetus (Fig. 2) the plane of the septa has attained an obliquity which is at an angle of about $45^{\circ}$ to the median plane, and this is the approximate angulation that has been encountered in all older foetal and adult specimens in which the heart has been sectioned in situ. All observations have led me to the conclusion that rotation of the heart occurs early in development and is completed during the first half of intra-uterine life. This is not in keeping with statements such as that of Baxter (1953) where it is claimed that the rotation does not occur till "towards the end of intra-uterine life".

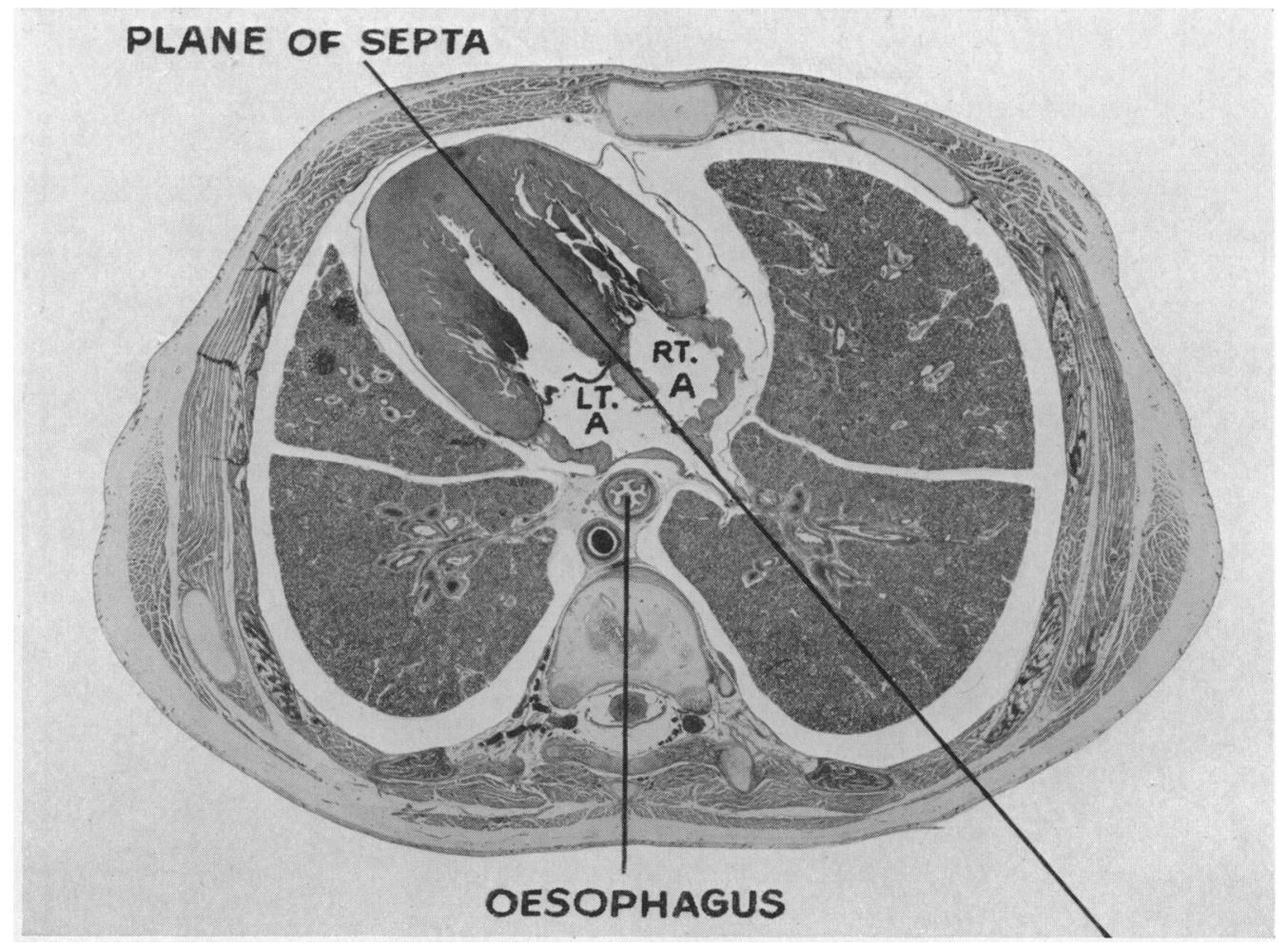

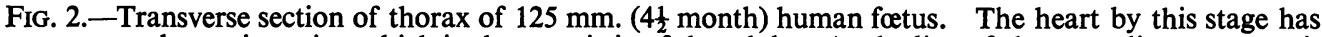
assumed an orientation which is characteristic of the adult. As the line of the septa lies at approximately $45^{\circ}$ to the mid-line plane, the right heart is as much in front of left heart as it is to its right. The great size of the right lung as compared with the left at this horizontal level is a very obvious feature of the section. Magnification, $\times 3 \frac{3}{4}$.

The fact that the plane of the septa assumes an obliquity that is between $41^{\circ}$ and $45^{\circ}$ to the median plane causes the right heart in older fotuses and in post-partum hearts to be almost, if not as much, in front of the left heart as it does to its right side. This is obviously a feature of cardiac anatomy that is of fundamental significance to both the clinician and the anatomist.

Another relevant fact in the rotation of the heart would appear to be that like all other growth processes, it is in complete harmony with the growth of the surrounding structures and the organism as a whole. It is very noticeable in the study of transverse sections of embryos that while the heart rotates to the left, the right lung attains a greater size than the left, and the right lobe of the liver, growing more quickly than the left, reaches a more cranial level.

This brief statement on the development of the oblique lie of the heart within the thorax is primarily to emphasize that the terms "right heart" and "left heart" are appropriate developmentally and also that the change from a symmetrical to an asymmetrical orientation of the heart 
occurs relatively early and is harmoniously associated with the asymmetrical growth of adjacent organs.

\section{MATERIAL AND METHOD}

The early observations on the rotation of the heart were made on a fairly large series of human embryos ranging in size from $8 \mathrm{~mm}$. (5th week) to $25 \mathrm{~mm}$. (8th week); all of these embryos had been cut serially, most of them transversely but some sagitally, and they form part of the embryological collection belonging to this Department. Some of the fœtuses, i.e. when the embryo had gained a length of more than $25 \mathrm{~mm}$. (after the 8th week of development) were also, when specimens did not exceed $40 \mathrm{~mm}$. in length, cut serially, but single sections of the larger fotuses were taken at appropriate levels of the thorax and did not always represent part of a continuous series. Eleven full-time fœetuses were cut transversely in sections that varied in thickness from $200 \mu$ to $25 \mathrm{~mm}$. ( 1 inch). Some of the sections were prepared by the technique described by Gough and Wentworth (1949) for the sectioning of whole lungs and the decalcification that was necessary was carried out by 4 per cent nitric acid. The thicker sections were made without decalcification after the thorax had been frozen, either by 48 hours in a refrigerator at $-15^{\circ} \mathrm{C}$. or by freezing in methylated spirit to

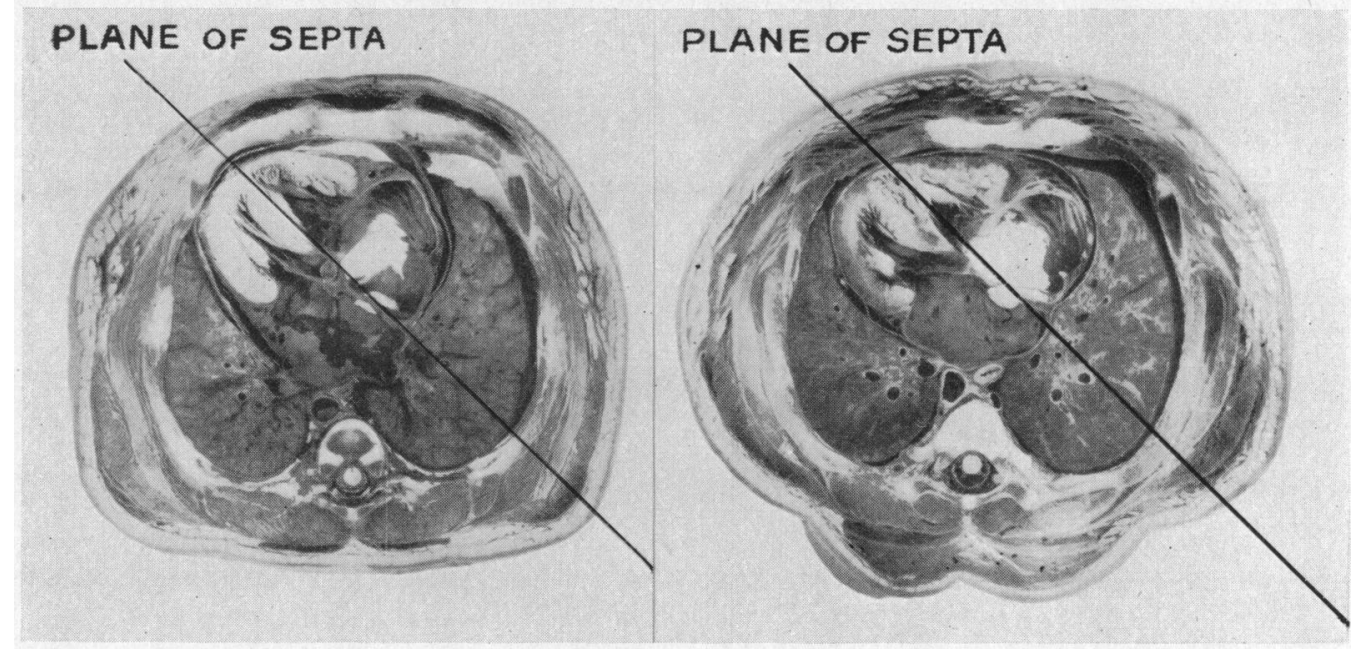

FIG. 3.-Transverse sections through thoraces of two full-time fœtuses. These fœtuses show a difference in the form of their thoraces but this has not caused any apparently great difference in the plane of the heart septa. Magnification, $\times \frac{1}{2}$.

which carbon dioxide snow was added. Thereafter these sections were cut on a bandsaw and after re-freezing the surfaces were smoothed by sand-papering. The latter method was employed in the preparation of sections of ten adult thoraces which were cut in transverse, sagittal, or oblique planes. No difficulty is encountered in the preparation of transverse or sagittal sections, except that it is essential that the specimens be frozen throughout if satisfactory sections are to be obtained.

In preparing sections of the right or left hearts, i.e. sections parallel to the septa of the heart, it was always assumed that the atrial and ventricular septa lay at an angle of $45^{\circ}$ to the median plane. Photographs of previously prepared transverse sections were, moreover, brought to the approximate scale of the thorax to be sectioned and the distance to the left of the mid-line in front and to the right of the mid-line posteriorly were calculated by reference to these prints before the plane of the "cut" was finally determined. The great variation in the form of thoraces renders it essential for the transverse section that is used to be from a cadaver of the same sex and of approximately that same body type as that on which it is proposed to make the oblique sections. 
Similarly, in planning sections of the thorax to show the heart cut transversely to the plane of the septa, it was always assumed that the septa of the heart were at an angle of $45^{\circ}$ to the median plane, and again by reference to prints of the correct size, sex, and body type, the distances from the midline in front and to the left of the mid-line posteriorly were plotted before the sections were made.

The writer has on each occasion been impressed by the close correlation between the desired and the actual plane of section when the requisite calculations were made beforehand. The procedure, if it is to be successful does, however, require experience in the preparation and cutting of frozen tissues with a mechanical saw and this will be most easily attained by working with someone who is already versed in the technique.

\section{Axis of the Heart and the Plane of the SePta}

It is not intended to infer that the plane of the septa as has been described is similar to what is termed the "axis of the heart". The axis is described by Walmsley (1929) as a line which extends from the centre of the base of the heart to its apex and thus passes from behind forwards, downwards, and to the left. The downward inclination of this axis is known to differ considerably

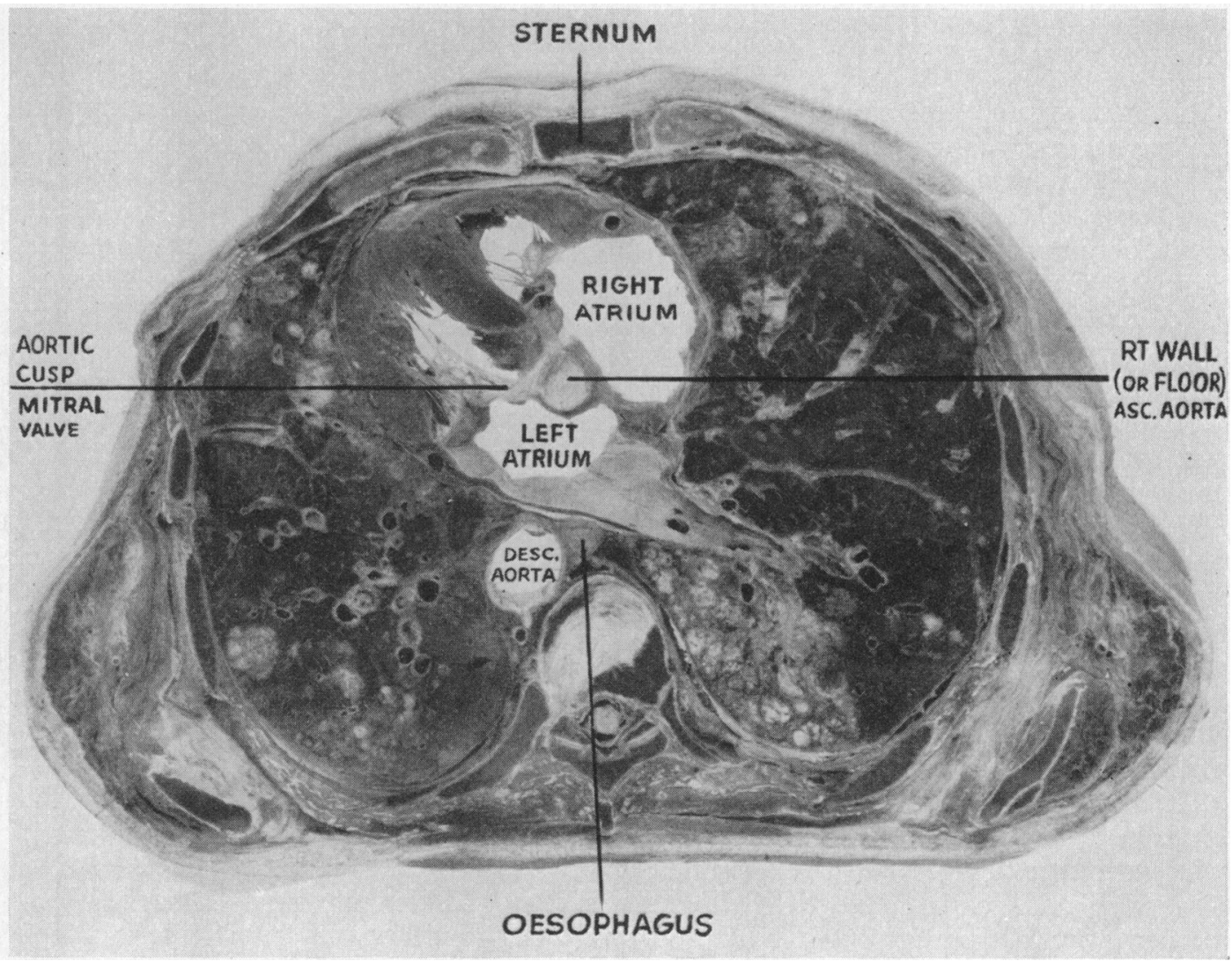

FIG. 4.-Transverse section of adult thorax at the level of the fourth costal cartilages. The section shows all four chambers of the heart, and the obliquity of the septa separating right from left hearts is obvious. The right atrium is dilated, and opening into the left atrium immediately to the left of the atrial septum is the lower right pulmonary vein. A small part of the right wall (or floor) of the ascending aorta is seen immediately adjacent to the aortic cusp of the mitral valve. It may be observed from this section that the blood in passing from atria to ventricles passes forwards and to left through the atrio-ventricular orifices at an angle of approximately $45^{\circ}$ to the median plane. The tricuspid valve is fairly closely related to the sternum whereas the mitral valve is much more deeply placed in the thorax. 
in living subjects. From the observations that I have been able to make, it would appear that the long axis of the heart is more horizontal in the cadaver than it is in the living (Fig. 6 and 7) and the heart as a whole lies at a higher level. The plane of the septa no doubt also differs considerably in living people but no great difference has been encountered among the eleven full-time fætuses and the ten adult cadavers sectioned, irrespective of sex or body build. The plane of the septa in all specimens ranged between $41^{\circ}$ and $45^{\circ}$ to the median plane, but it is appreciated that there may be post-mortem or technique factors that determine this apparent uniformity. It would ill-serve the purpose of this communication to attempt to claim that the form of the heart chambers shown in the photographs of cadaver specimens have their exact counterpart in the living; it is hoped, however, that the photographs here included may form a contribution to a better understanding of living cardiac anatomy.

Fig. 3 is included to show the plane of the septa in two full-time fœtuses that differed fairly strikingly in their thoracic form-a difference that in part is due to a difference in body build and also, as is apparent, to post-mortem artefacts.

A small print of the section shown in Fig. 4 is placed below each of the photographs of the oblique sections, and the plane of each section is indicated on these smaller prints.

\section{Discussion}

It is not proposed to enter into a discussion of the many anatomical relationships of importance that have become increasingly apparent during the preparation and examination of these sections, and it would be invidious to discuss the vast literature on this subject. It has perhaps been unfortunate, however, that so many of the classical diagrams of the heart have been made from specimens that had been removed from the body and orientated so that the atria are featured as lying above the ventricles. Current papers, however, more and more tend to consider the heart as it lies in situ, e.g. Bedford et al. (1957), and this study is based on specimens examined in this way. The atria lie not only behind the ventricles, but to an almost equal extent to their right, and this relationship is determined by the obliquity of the "plane of the septa". Moreover the relationship of the ventricles to each other is erroneously depicted in many standard texts; transverse sections of the ventricles in such figures, for example, show the ventricular septum lying in approximately a sagittal plane with the right ventricle lying almost entirely to the right side of the left ventricle.

The value of the included photographs and observations in the legends is in itself limited. On account of the oblique orientation of the heart in the chest the radiologist not only views it from the front or back but also, as one would expect, resorts to right and left oblique radiographs. It is intended, therefore, that one of the functions of these photographs is to help to clarify certain anatomical features of the heart and great vessels as they are seen in these oblique views. The photographs of specimens cut parallel to the plane of the septa may be compared with radiographs taken in the right anterior oblique position, whereas photographs of specimens cut at right angles to the septa may be correlated with the heart shadow as seen in the left anterior oblique position.

The relationship of the aortic cusp of the mitral valve to parts of the posterior cusps of the aortic valve is extremely close and indeed the bases of these cusps overlap. The proximity of these parts of the two valves is such that it is difficult to understand how from an X-ray film alone it would be possible to differentiate which of the valves is involved in a disease process such as calcification; the movements of a calcified valve on screening may, on the other hand, be of value in reaching a diagnosis.

The rotation of the heart, which as emphasized occurs in the first half of intra-uterine life, causes the left atrium to become indirectly related to the middle thoracic vertebræ thereby forming the posterior surface or base of the heart. The left atrium forms the major cardiac relation of the œsophagus but the "left horn" of the right atrium and also a small part of the left ventricle are in contact with it. Fig. 13 shows fairly clearly the close relationship that exists between a part of the left bronchus and the left atrium and is one of the main reasons for including this photograph. 


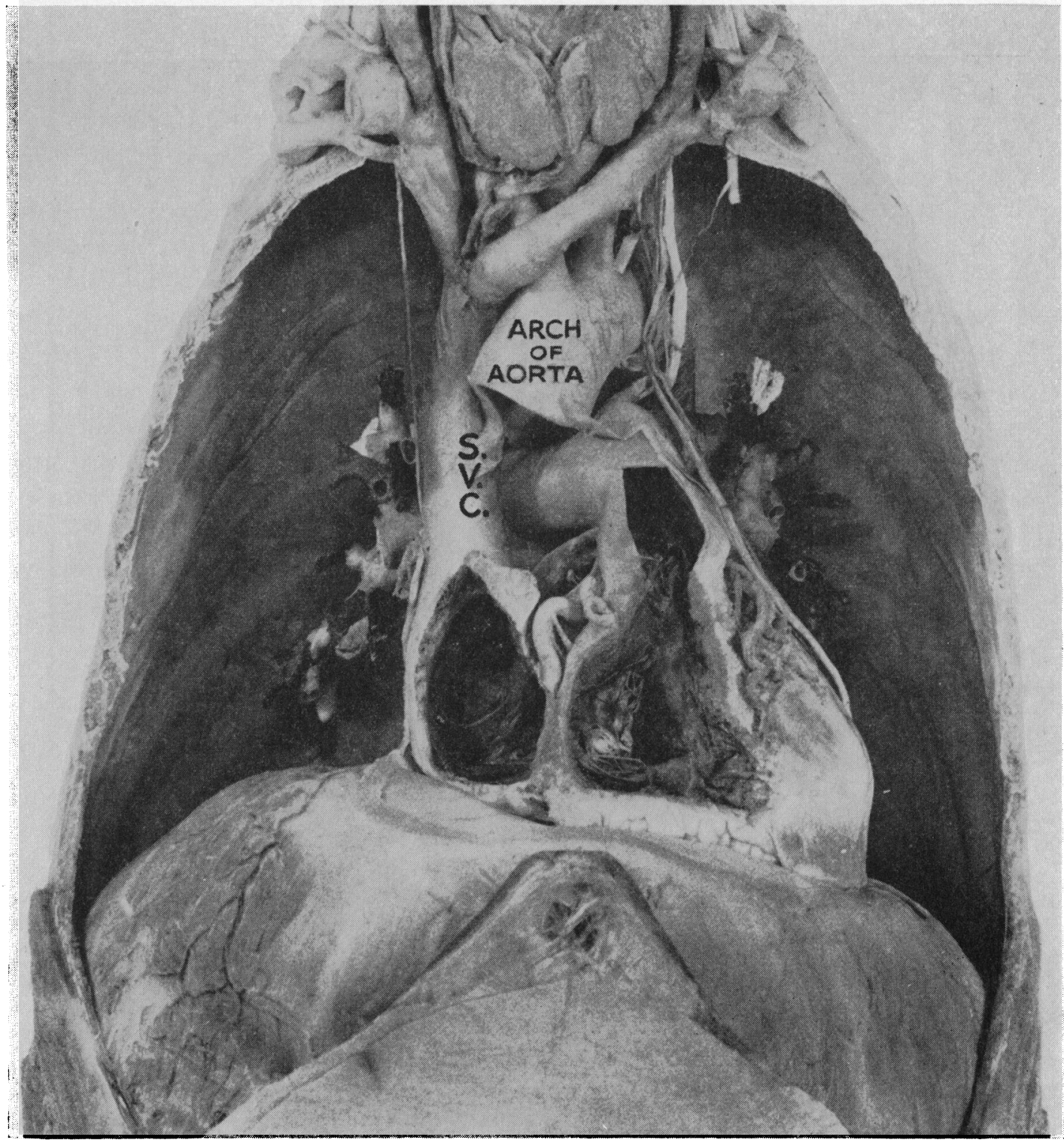

FIG. 5.-Thorax dissected from the front with the heart in situ. The anterior walls of the right atrium and ventricle have been removed along with part of the anterior wall of the pulmonary trunk. The right atrium, as is customary in cadavers, is dilated and in it a wellmarked valve of the inferior vena cava may be seen. The right border of this atrium is seen to be continuous with the superior vena cava. The greater part of the ascending aorta was removed to expose the right pulmonary artery. The left ventricle, which was not opened, is seen to form the left border of the heart, and when it is followed upwards it is seen to be in line with the left border of the pulmonary trunk. The left auricle frequently embraces the beginning of the pulmonary trunk but it was small in this specimen and is not seen in this view. Above the termination of the pulmonary trunk lies the aortic arch but between the two structures is a gap which is termed the "aortic window". 


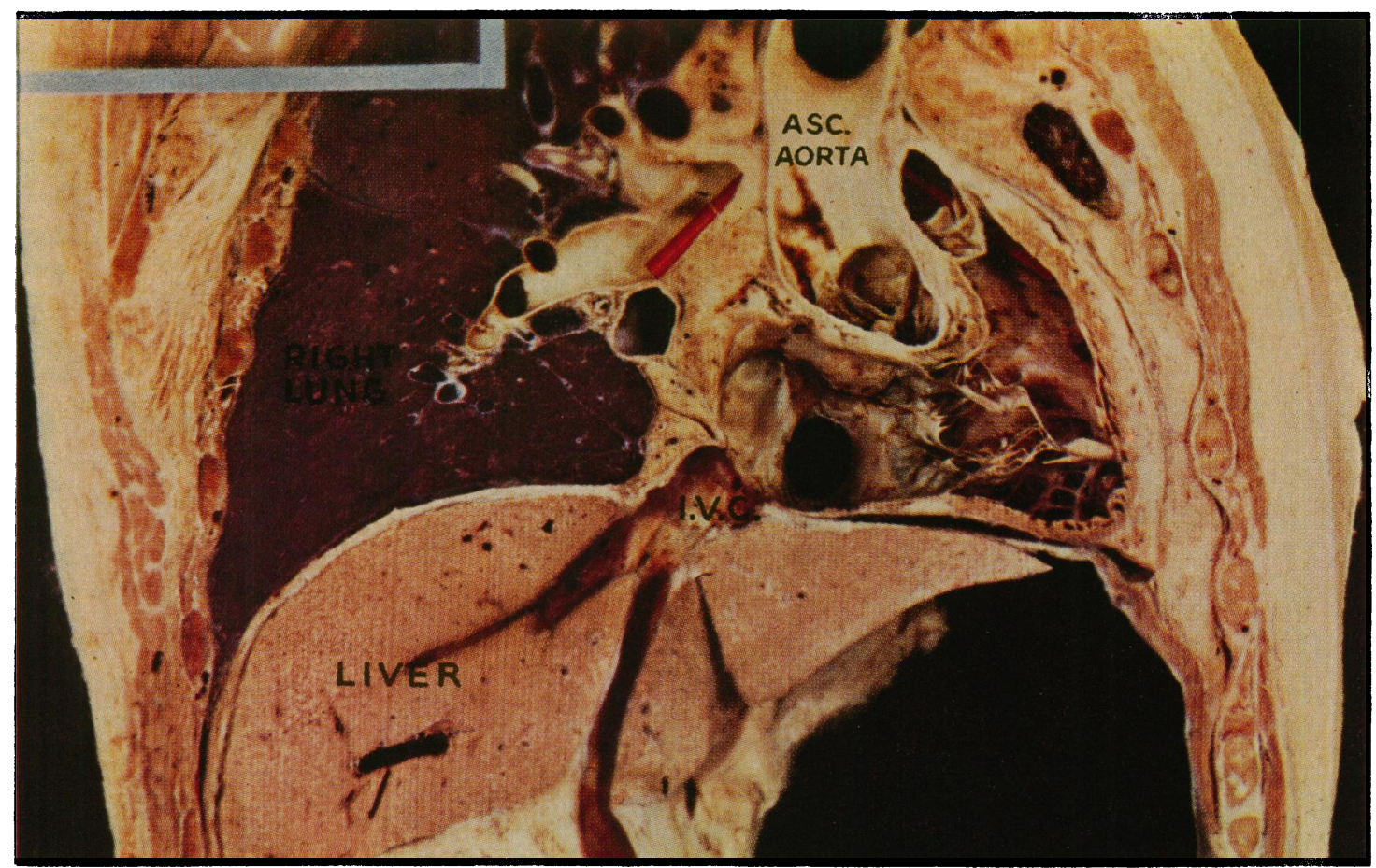

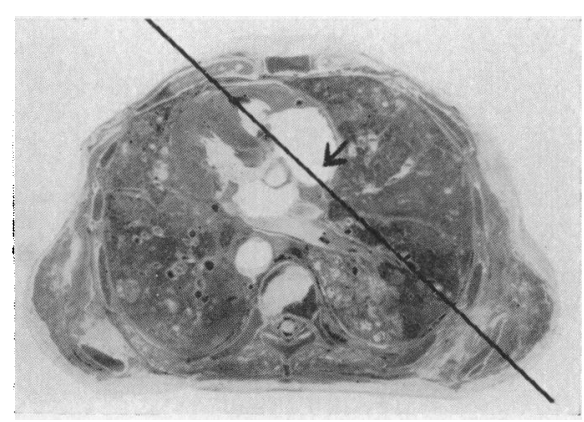

Continuous line indicates plane of section

FIG. 6.-Section through right heart viewed from right side and cut in plane shown below. The inferior vena cava is seen passing through the diaphragm obliquely to enter the right atrium, but the superior vena cava is not shown. Immediately in front of the inferior caval opening is the "left horn" of the right atrium (which is occupied by a blood clot) and leads into the coronary sinus; it extends to the left for a short distance below the left atrium and is the only part of the right atrium that is related to the œsophagus. The cusps of the tricuspid valve are prominent and the cavity of the right ventricle has the typical U-shaped form. The infundibulo-ventricular (supra-ventricular) crest is fairly prominent and bounds the infundibulum posteriorly. The cusps of the pulmonary valve are visible and lie at a higher level than those of the aortic valve. The horizontal lie of the diaphragmatic surface of the heart may partly be due to the fixation of the cadaver in a supine position, but it is significant that the orientation of this surface is that which has been encountered in all adult specimens examined. The diaphragmatic surface might equally appropriately be termed the inferior surface. 


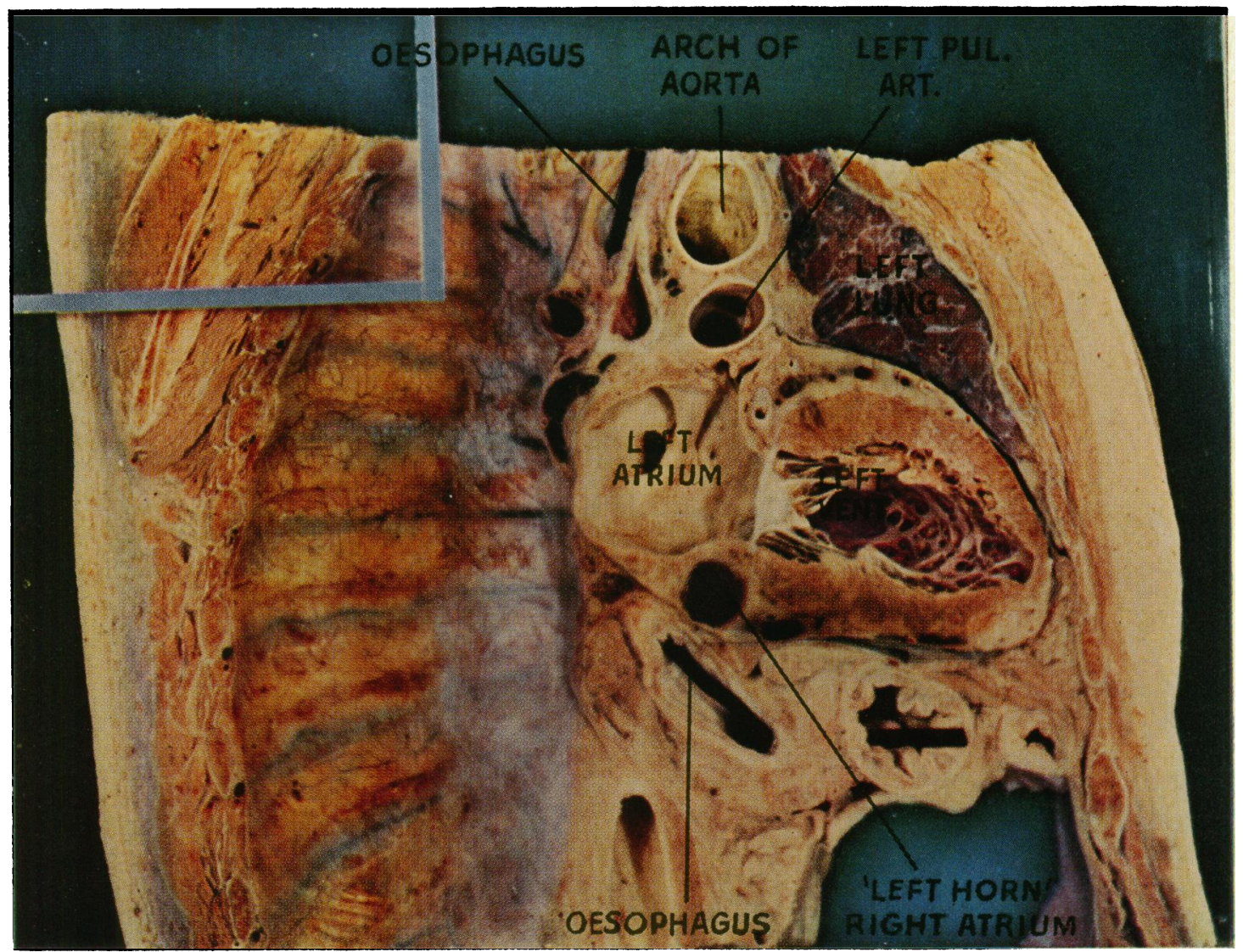

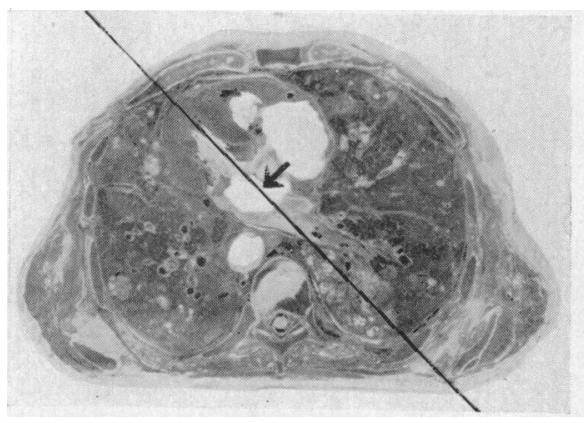

Continuous line indicates plane of section

Fig. 7.-Section through left heart viewed from right side and cut in plane shown below. The left atrium and left ventricle are shown with the mitral valve in between. The "left horn" of the right atrium (filled with blood), which leads into the coronary sinus, lies below the body of the left atrium. A tube was passed along the œsophagus and has been left in situ. The œsophagus is here seen to lie behind the left atrium but a small terminal part is related to the "horn of the right atrium". The lower end of the tube emerges from the stomach: this serves to illustrate the close relationship that exists between heart and stomach. The part of the right lung that lay behind the heart was removed to show the posterior part of the thoracic wall: a small part of the left lung was left in situ in relation to the sterno-costal surface of the heart.

It will be seen from Fig. 7 that the blood in its passage from left atrium to ventricle passes forwards and to the left at an angle of about $45^{\circ}$ to the median plane. As seen in Fig. 6 and 7 there is little, if any, downward inclination of the blood during its course through the atrio-ventricular orifices. 


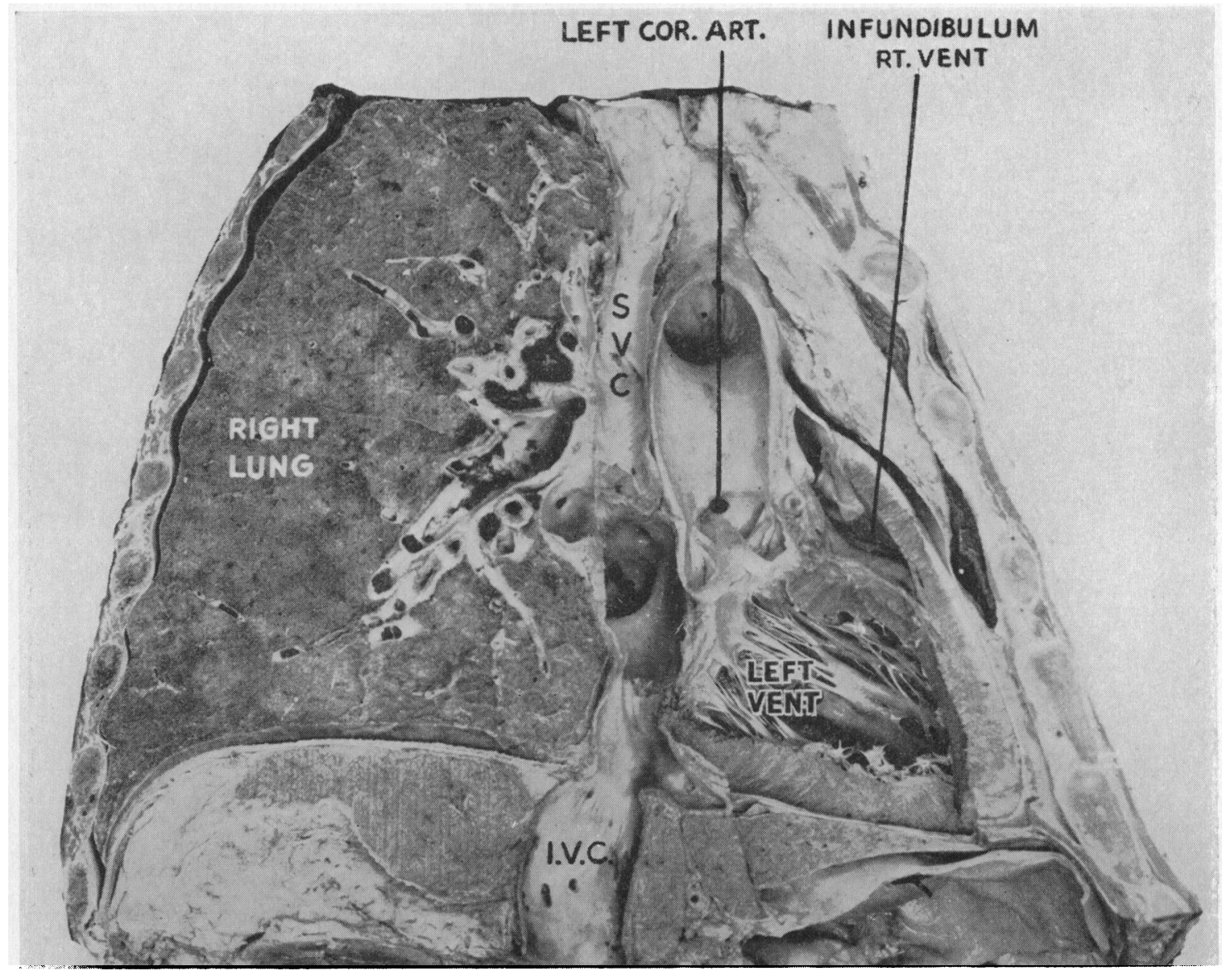

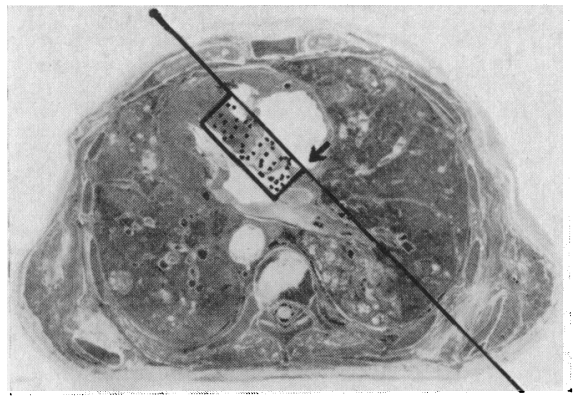

Continuous line indicates plane of section after removal of stippled area

Fig. 8.-Section showing interior of left atrium and left ventricle with the aortic valve and part of ascending aorta in situ; the specimen was cut in plane shown below and then the atrial and ventricular septa were removed.

This section and dissection were made to establish the relationship of the cusps of aortic and mitral valves to each other. A large window was cut in the right wall of the ascending aorta, but the entire aortic valve was left intact. The aortic cusps are attached very obliquely so that their upper surfaces are directed almost as much to the right as they are upwards. The aortic cusp of the mitral valve is much larger than the posterolateral one. The base of the aortic cusp of the mitral valve extends upwards to the attachments of the adjacent parts of the posterior cusps of the aortic valve. 


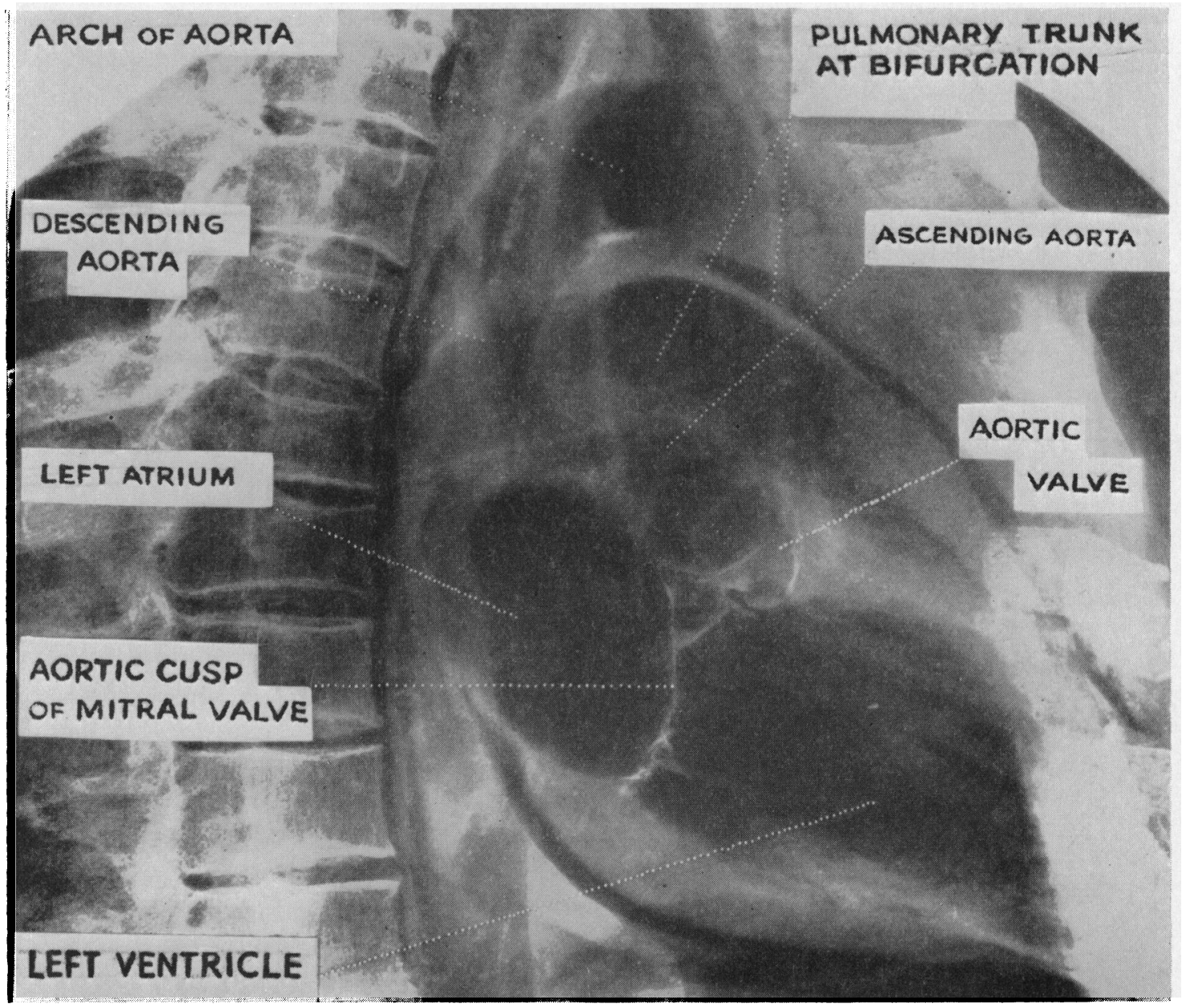

FIG. 9.-The bases of the cusps of the mitral and aortic valves of specimen shown in Fig. 8 were coated with a paste of barium sulphate. There were, moreover, a few calcareous nodules in the cusps of the aortic valve. The specimen was X-rayed and this figure is a print from the untouched radiograph. The close relationship of the upper part of the aortic cusp of the mitral valve to the cusps of the aortic valve is a striking feature and it would appear to make difficult in an Xray film the differential diagnosis between calcification of the posterior aortic cusps and the aortic cusp of the mitral valve. This radiograph is reproduced at approximately the same magnification as Fig. 8. 


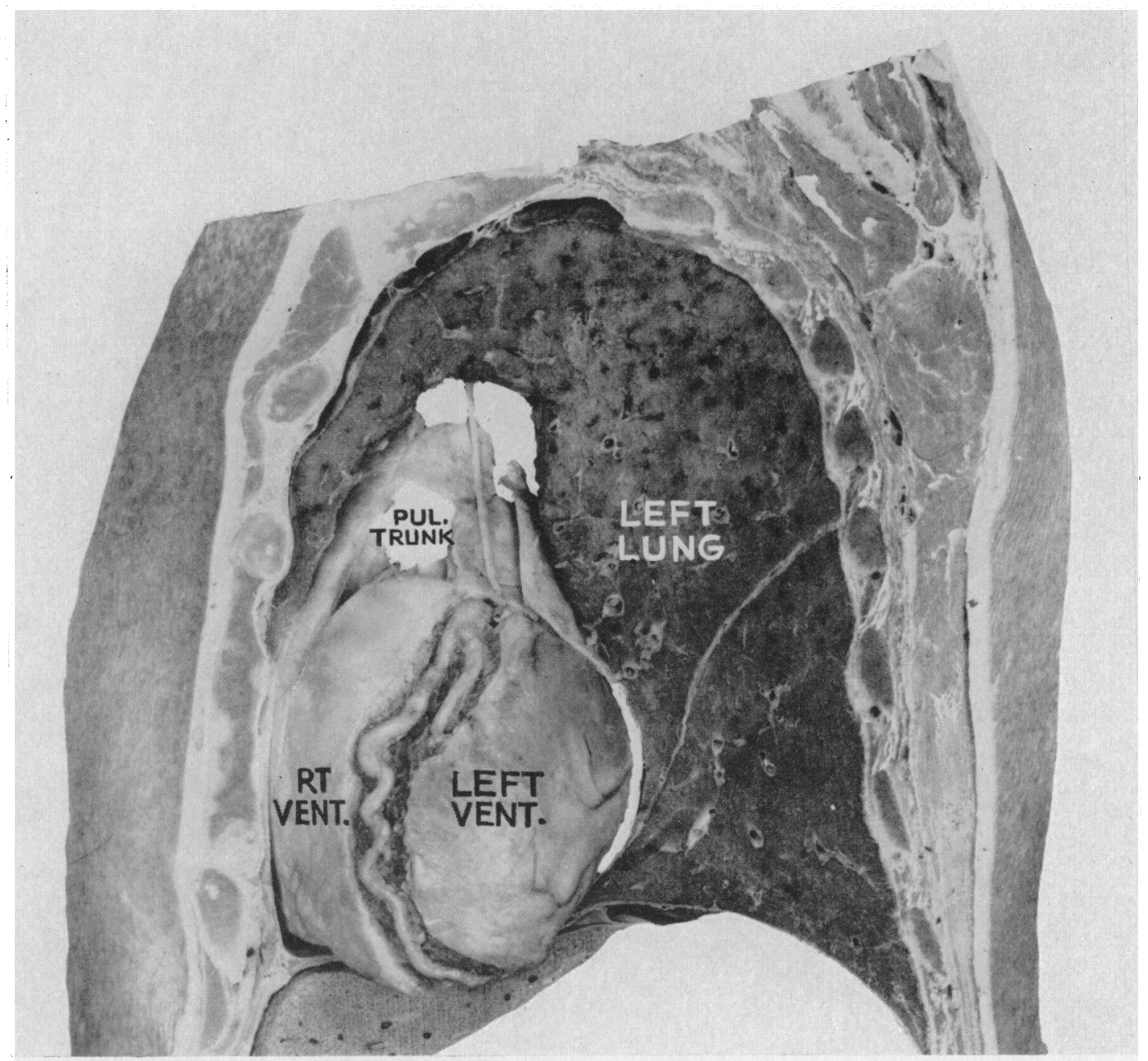

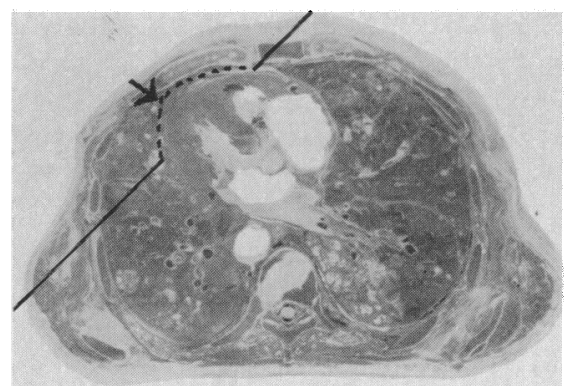

Continuous and interrupted lines indicate plane of section
FIG. 10.-This is one of a series (Fig. 10 to 13 , inclusive) in which the heart is viewed along the long axis of the septa. In each of these specimens the heart is viewed from the front and left sides, and together they are equivalent to the view of the heart and great vessels as seen in the left anterior oblique position.

In this specimen the apical part of the heart was removed in the section of the thorax and then replaced before the photograph was taken. The interventricular branch of the left coronary artery lies in the corresponding anterior sulcus and the right ventricle lies in front of it and the left ventricle behind it. A window has been cut in the pulmonary trunk and a part of the left lung adjacent to it has been removed: the left phrenic nerve is seen descending in the space created. 


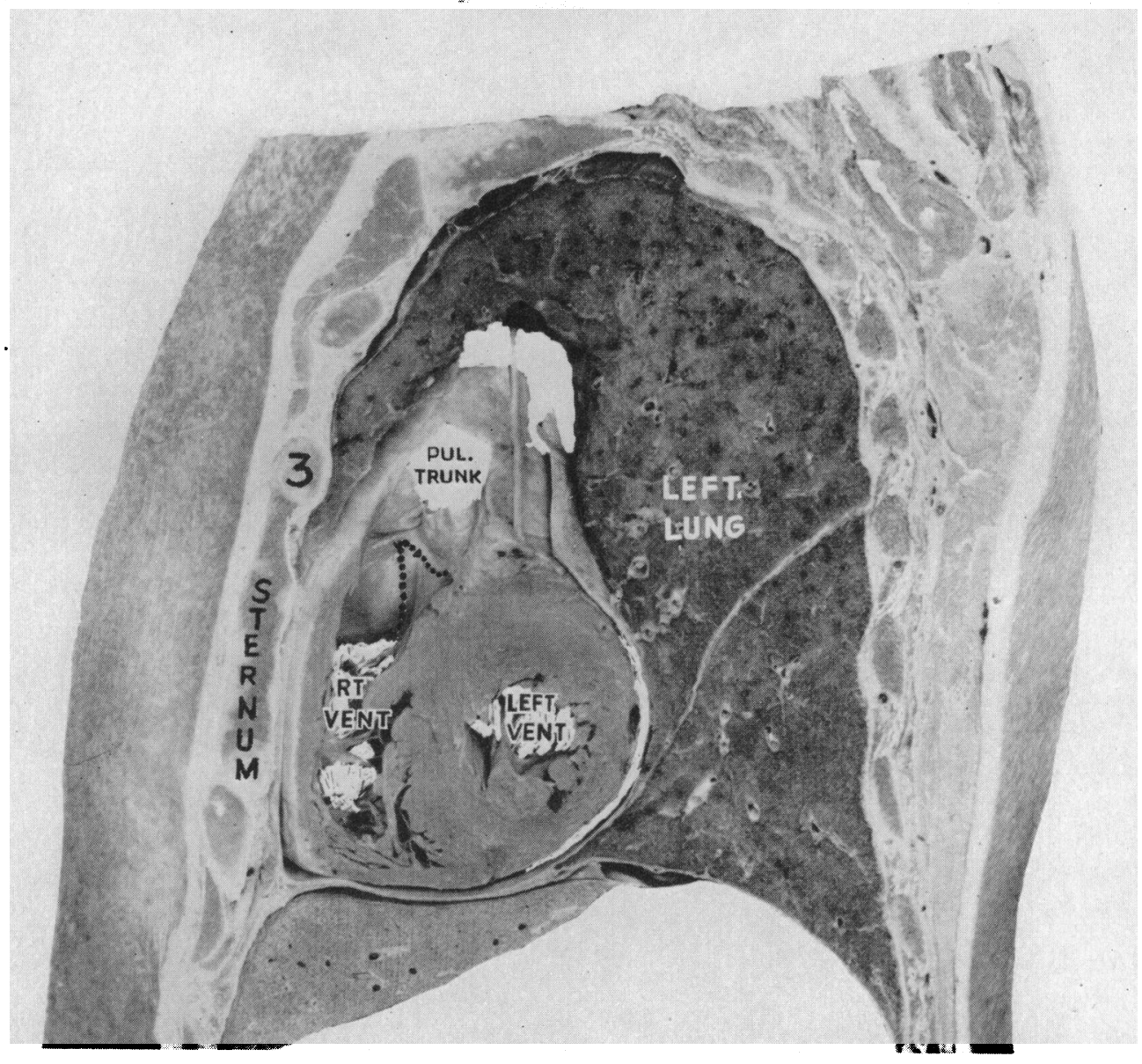

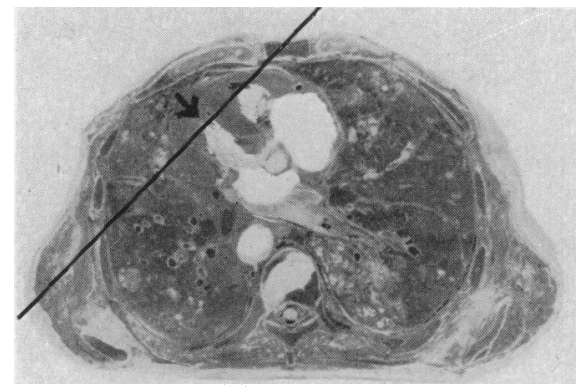

Continuous line indicates plane of section

FIG. 11.-This is the same specimen as that seen in Fig. 10, but the apical part of the heart has been removed as shown below. The heart is cut at right angles to the plane of the ventricular septum and the right ventricle thus lies directly in front of the left; the walls of these chambers have their characteristic form. The window in the pulmonary trunk allows two cusps of the pulmonary valve to be seen, and below this is the infundibulum which constitutes the outflow tract of the right ventricle. The pulmonary cusps lie at the level of the third left costal cartilage (3) at its junction with the sternum and the close relation of the outflow tract of the right ventricle with the sternum just below this level is evident.

On the other side of this section, parts of the anterior and left posterior cusps of the aortic valve were attached and pins were passed through to indicate the relationship of their attachment to the infundibulum. These attachments have been "dotted in" and the part of the anterior cusp is seen as a vertical row of dots with the left posterior cusp attachment extending backwards from its upper end. The aortic valve is very obliquely placed and lies at a lower level than the pulmonary valve. 


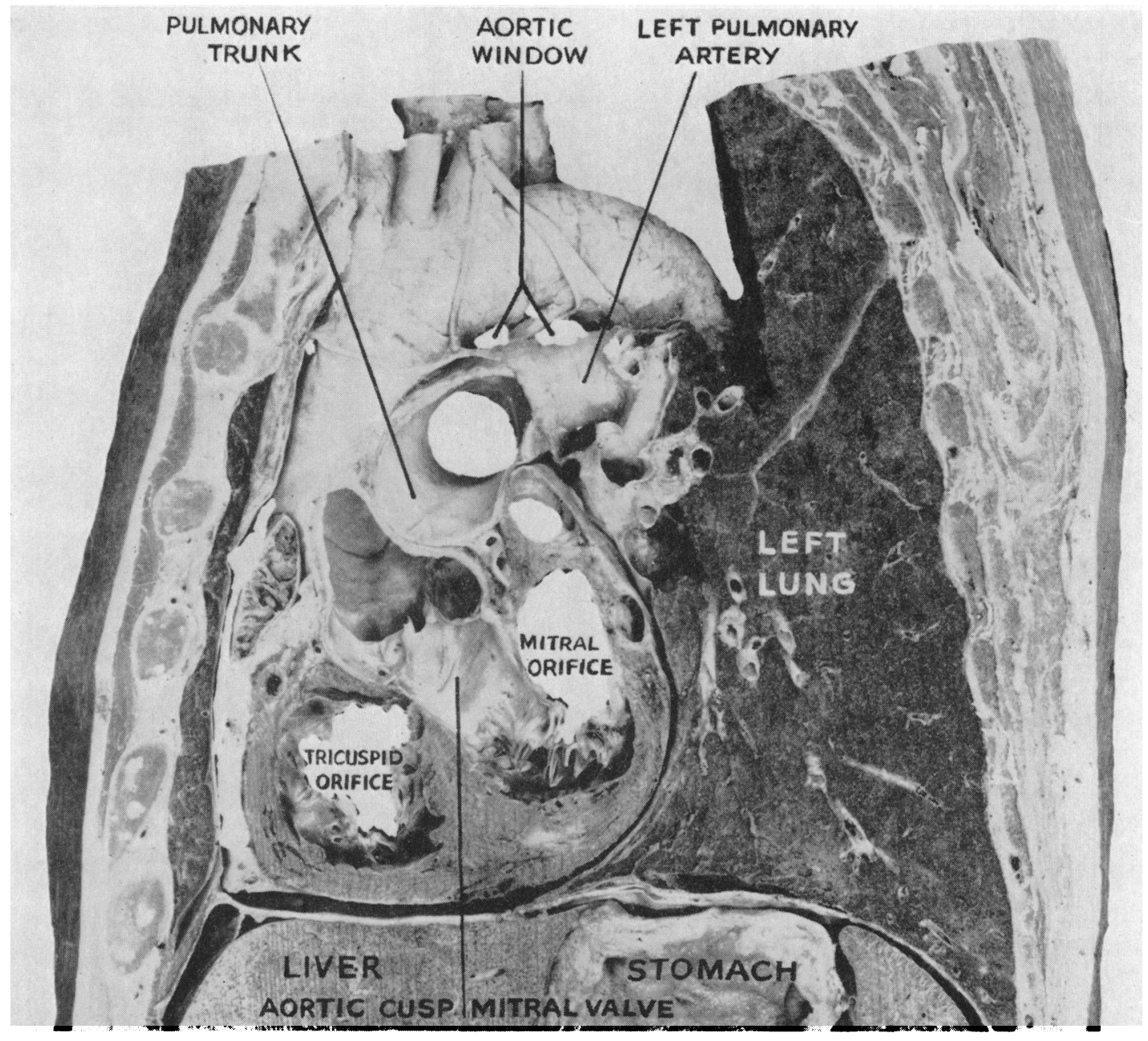

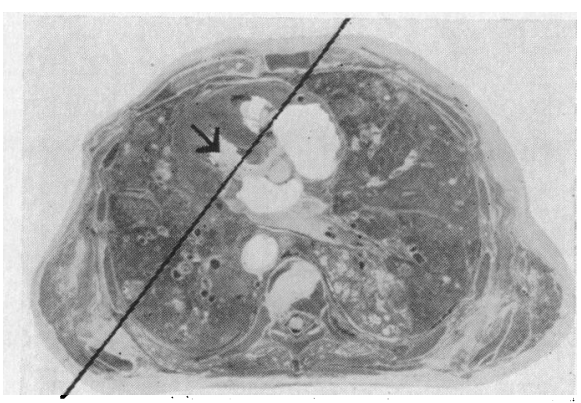

Continuous line indicates plane of section

FIG. 12.-This section is at right angles to the septa of the heart and passes through both atrio-ventricular valves (see small figure below) and also the aortic valve. The close relationship between the large aortic cusp of the mitral valve and the cusps of the aortic valve is evident. A part of the right lung is seen in front of the heart but the left lung lies behind it. Between the left pulmonary artery and the under-surface of the arch of the aorta there is the potential space, termed the aortic window, in which the ligamentum arteriosum is seen to lie.

The ventricular surface of the aortic cusp (which is shown) is smooth and this is the structure that forms the posterior wall of the aortic vestibule. The course of the blood from left atrium to aorta is sinuous as may be appreciated by a study of this photograph. 


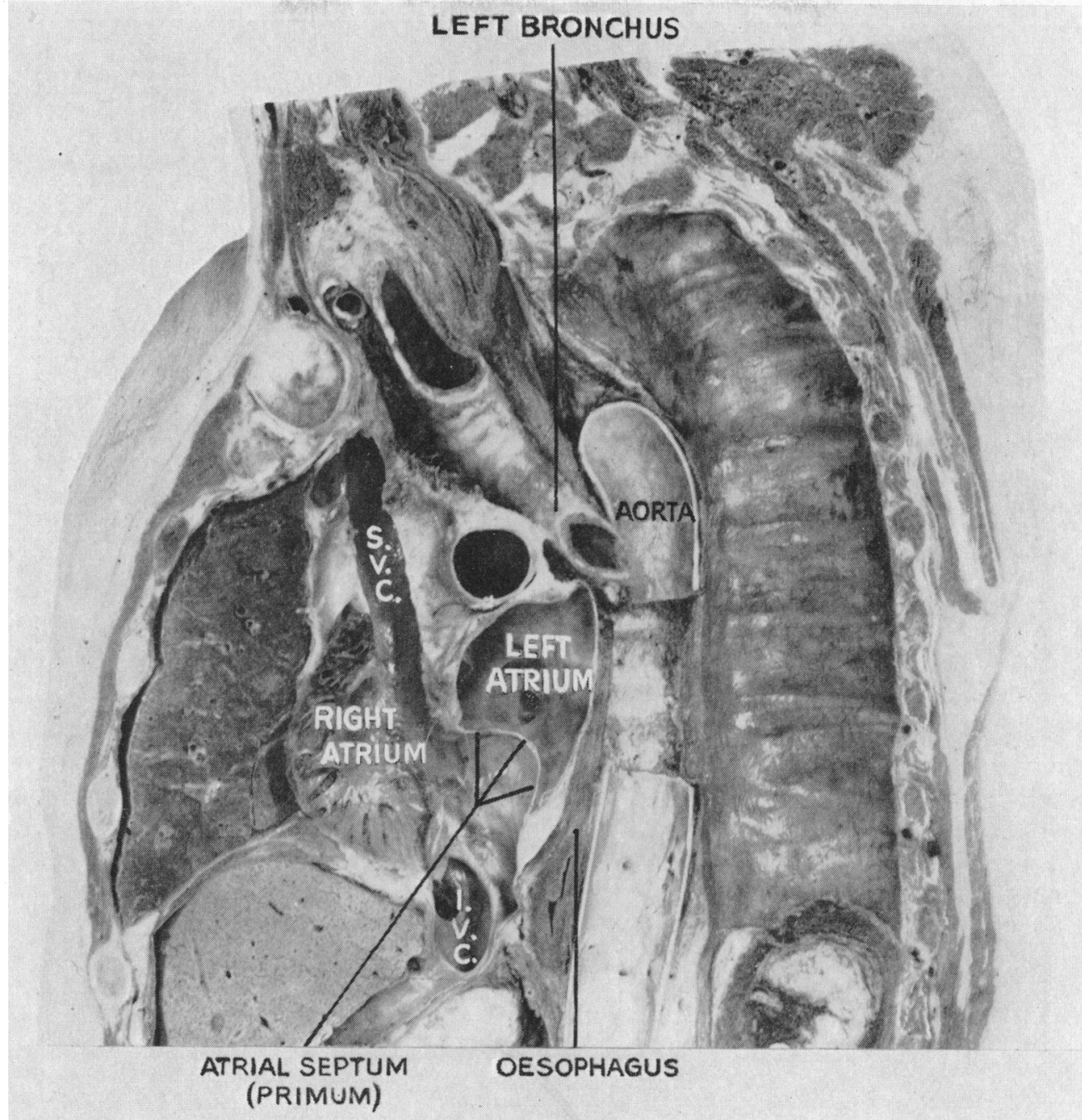

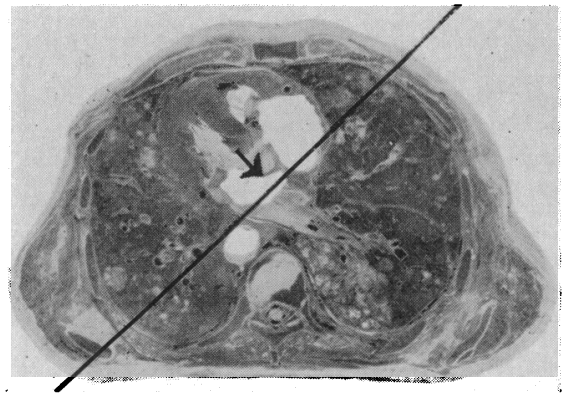

Continuous line indicates plane of section

Fig. 13.-This section is at right angles to the atrial septum and passes through both right and left atria in the plane shown below. The septum primum, which forms the floor of the fossa ovalis, has its customary thinness, whereas the septum secundum, which lies above it, is thick. Both the superior and inferior venæ cavæ are seen opening into the right atrium. The esophagus may be distinguished passing down behind the left atrium but at its lower end it comes into relationship with the right atrium. The right pulmonary artery lies directly above the left atrium and behind it is the left bronchus. From this photograph it would appear that the contact of left bronchus with left atrium was over only a very short distance, but this is not so, as at least $12 \mathrm{~mm}$. $(0.5 \mathrm{inch})$ of the posterior wall of the left atrium was removed to expose the œsophagus and a corresponding part of the left bronchus was likewise resected. 


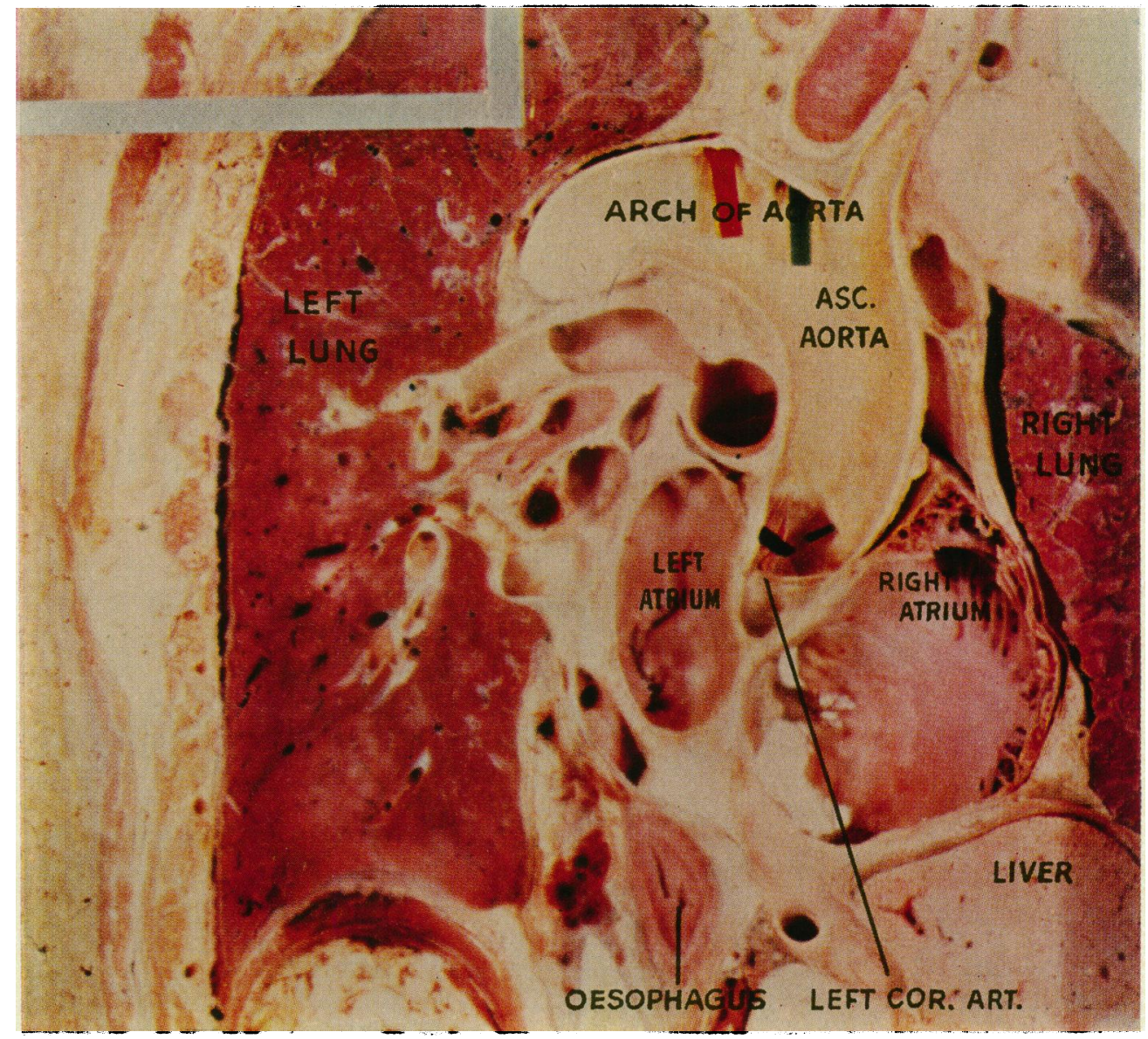

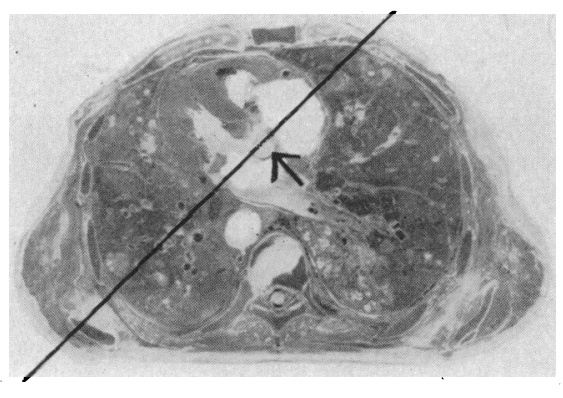

Continuous line indicates plane of section

FIG. 14.-This section is of a series different from the four immediately preceding. Although it is sectioned in the same plane, i.e. at right angles to the heart septa, it is viewed from the right and behind so that the photograph has been taken looking from the atria towards the tricuspid and mitral orifices (see small figure below).

The cusps of the atrio-ventricular valve project forwards and to the left into the corresponding ventricle. The close relationship of the cusps of the aortic valve to the aortic cusp of the mitral valve is again evident. Glass rods have been inserted into the left common carotid and left subclavian arteries and are very obvious, and rods in the coronary arteries may also be seen.

It is obvious from this section that the aortic cusp of the mitral valve might equally well be termed the "antero-medial" cusp and this would be in keeping with the use of the term "postero-lateral" for the opposing cusp of that valve. 


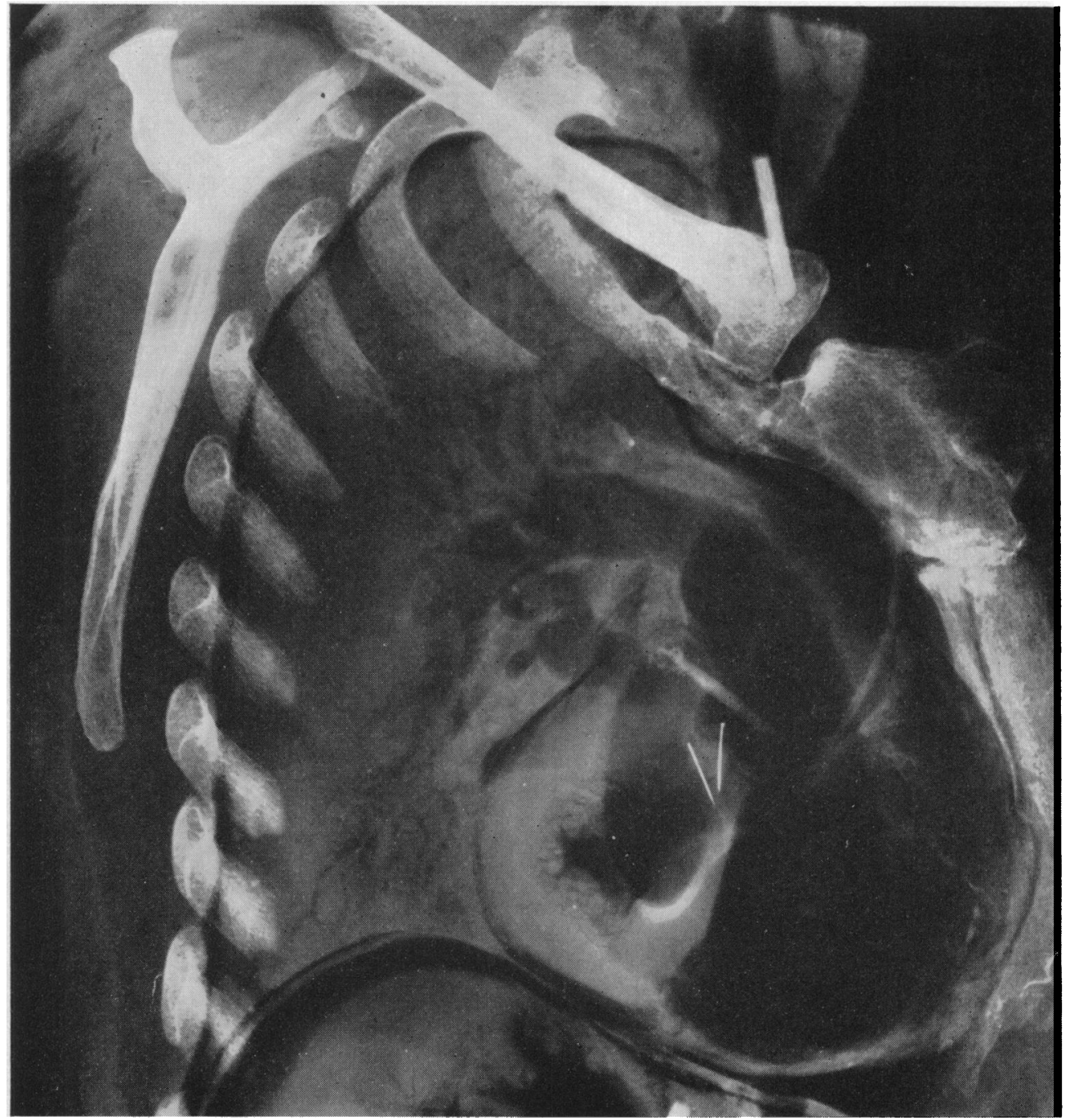

FIG. 15.-This X-ray is of the same specimen shown in Fig. 14 and is of the same magnification. One pin was inserted as nearly as possible into the attachment of part of the right posterior cusp of the aortic valve and another was inserted along the line of attachment of the upper part of the aortic cusp of the mitral valve. The specimen was then radiographed and the close relationship of the pins is very evident. The thick wall of the left ventricle as seen here is not visible in Fig. 14, but many other features may be correlated with the photograph. 
This communication is primarily a plea that gross cardiac anatomy should always be considered with the heart lying in situ. This, it is believed, is the only means that will allow the surfaces, the cusps of the valves, and other structures to be designated by names that are precisely appropriate to them, and what is more important, give an understanding of the relative position of the heart chambers, valves, and great vessels to one another. When the heart has been removed post-mortem, it shows changes in its form and is easily distorted so that it is difficult to reconstitute the shape that it had in the body, either before or after death.

\section{SUMMARY}

The human heart in young embryos is approximately symmetrical with the atrial and ventricular septa almost in the median plane. A rotation occurs which carries the anterior interventricular sulcus to the left and after about $4 \frac{1}{2}$ months of intra-uterine life the heart has assumed its adult position with the atrial and ventricular septa at an angle of about $45^{\circ}$ to the median plane.

Sections were prepared of the adult thorax by cutting with a band-saw after the specimen had been frozen. Sections were made parallel to the septa so as to pass through both the right and left sides of the heart: these may be of value in interpreting X-ray films taken in the right anterior oblique position. So, too, were sections made that cut the heart at right angles to the plane of the septa, and these may be considered with films taken in the left anterior oblique position.

Photographs of representative specimens constitute the major part of this contribution to the anatomy of the adult heart. Two of the photographs are supplemented by radiographs in which the aortic cusp of the mitral valve and parts of the posterior cusps of the aortic valve are indicated by radio-opaque substances.

The legends to the photographs make reference to some of the principal relationships. No review is made of the literature nor is it discussed, but a short discussion of the specimens is included.

A work of this nature requires the cooperation of several people. Foremost I should like to acknowledge my deep indebtedness to Professor I. G. W. Hill, not only for his very considerable help and guidance, but also for giving to me the initial stimulus to prepare the series of sections from which the selected photographs have been made. I also would like to record my thanks to Dr. J. W. Smith and J. Mutch who both assisted me in planning the plane of the sections and also in cutting the thoraces, and also to Mr. P. D. Bewsher for the dissection of the specimen shown in Fig. 5. The photography is the work of the senior technician of the Department, Mr. James Brown, and without his skill and patience this contribution could not have been made. I am indebted to Dr. W. F. Mair for the two radiographs.

\section{REFERENCES}

Baxter, J. S. (1953). Frazer's Manual of Embryology. 3rd ed., Baillière, Tindall \& Cox, London. Bedford, D. E., Sellors, T. H., Somerville, W., Belcher, J. R., and Besterman, E. M. M. (1957). Lancet, 1, 1255. Gough, J., and Wentworth, J. E. (1949). J. Roy. Microscop. Soc., 69, 231.

Walmsley, T. (1929). The Heart. Quain's Elements of Anatomy. 11th ed., Vol. IV, Pt. III., Longmans, Green, London. 